\title{
Outcomes in patients with contained ruptures of the aortic annulus after transcatheter aortic valve implantation with balloon-expandable devices
}

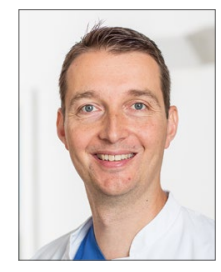

Philipp Breitbart ${ }^{1}$, MD; Jan Minners ${ }^{1}$, MD; Gregor Pache², MD; Philipp Blanke ${ }^{3}$, MD; Jochen Reinöhl' ${ }^{4}$, MD; Nicolaj Christopher Hansson ${ }^{5}$, MD; Bjarne L. Nørgaard ${ }^{5}$, MD; Franz-Josef Neumann ${ }^{1}$, MD; Philipp Ruile ${ }^{1 *}$, MD

1. Department of Cardiology \& Angiology II, University Heart Center Freiburg-Bad Krozingen, Bad Krozingen, Germany;

2. Department of Radiology, Section of Cardiovascular Radiology, University of Freiburg, Freiburg, Germany; 3. Department of Diagnostic and Interventional Radiology, St. Paul's Hospital, Vancouver, Canada; 4. Department of Cardiology \& Angiology I, University Heart Center Freiburg-Bad Krozingen, Freiburg, Germany; 5. Department of Cardiology, Aarhus University Hospital, Aarhus, Denmark

\section{Introduction}

Contained ruptures of the aortic annulus (CR) have been diagnosed as an incidental finding on computed tomography angiography (CTA) performed after TAVI with an incidence of up to $5 \%{ }^{1}$. Information on outcomes in patients with $\mathrm{CR}$ is limited ${ }^{2-6}$. Therefore, the aim of the present study was to evaluate long-term outcomes in patients with CR from a large European multicentre cohort with systematic post-TAVI CTA.

\section{Methods}

We report on 12 patients (out of a total of 1,030) who underwent post-TAVI CTA between July 2009 and July 2015 at three centres in Denmark and Germany. Data collection was performed via case report forms, and a final interview (by phone or via mail) was conducted in all patients between May and November 2016.

\section{Results}

The median interval from TAVI to diagnosis was $16 \pm 15$ days. Patient characteristics are summarised in Table 1. All patients had received a balloon-expandable valve (SAPIEN XT or SAPIEN 3; Edwards Lifesciences, Irvine, CA, USA). Mean degree of oversizing was $26.7 \pm 10.5 \%$. In three of the 12 patients, periprocedural transoesophageal echocardiography (TEE) revealed findings suggestive of aortic dissection, an aortic intramural haematoma, and/or a pericardial effusion. In the remaining nine patients, periprocedural echocardiographic monitoring, including TEE in seven patients, was unremarkable and the rupture was detected incidentally on postTAVI CTA. In nine cases (75\%), the contained rupture was found adjacent to the left coronary cusp, whereas the bulk of calcification was found next to the non-coronary cusp (Table 1). At the time of diagnosis, none of the patients was symptomatic, and no specific 
Table 1. Patient characteristics.

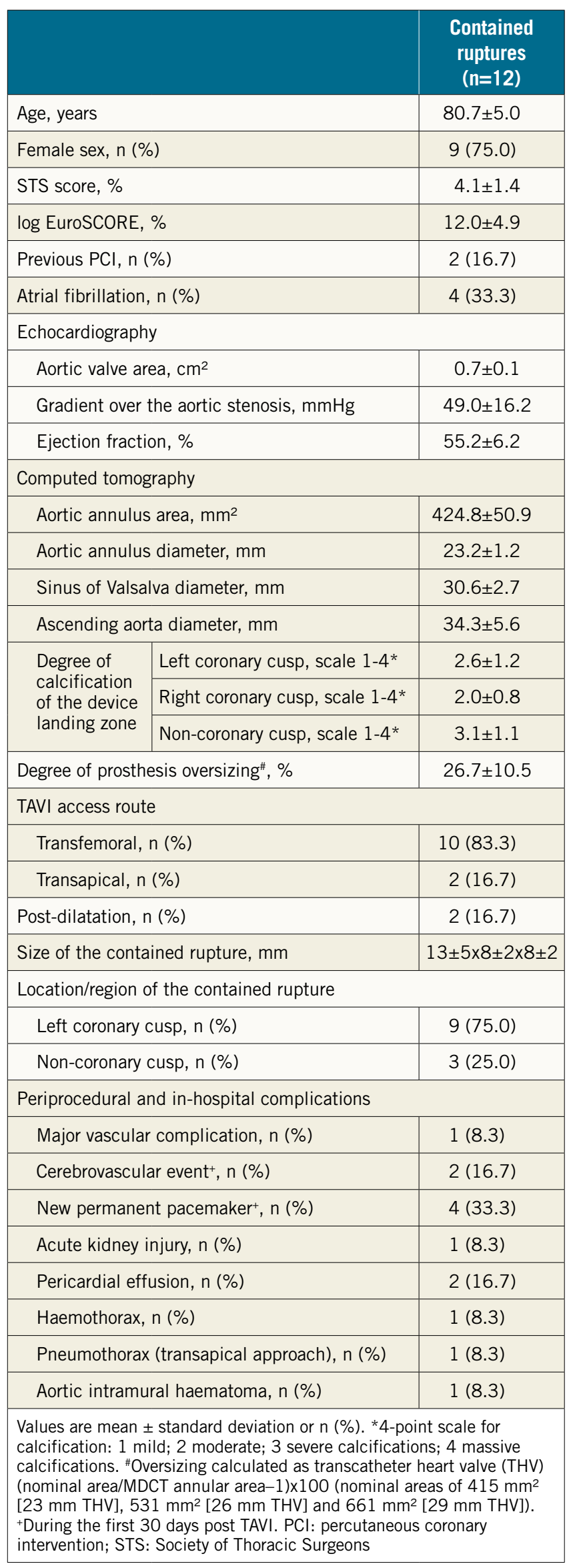

treatment related to the $\mathrm{CR}$ was initiated. During a median followup of $2.5 \pm 1.5$ years, none of the patients developed symptoms or died from CR-related causes. In five patients, follow-up-CTA was performed after $287 \pm 218$ days, three with stable findings and two with no longer detectable ruptures (Figure 1).

\section{Discussion}

To the best of our knowledge, this is the first study to investigate the long-term follow-up of patients with contained rupture of the aortic annulus after TAVI, documenting a benign course over a mean follow-up period of $2.5 \pm 1.5$ years. In none of our patients was a specific treatment necessary, and all remained asymptomatic during the follow-up period. This is in line with prior short-term follow-up studies, which demonstrated unchanged follow-up CTA and favourable outcomes up to six months ${ }^{1-4}$.

\section{Limitations}

Due to the clinical characteristics of our patient cohort, we achieved a post-TAVI CTA rate of $69 \%$. Therefore, a number of contained ruptures may have been missed and a higher incidence of this condition cannot be excluded. Although our observations are based on a large cohort undergoing TAVI, the number of patients with contained ruptures is limited as is the duration of follow-up.

\section{Conclusions}

The data presented suggest that previously reported favourable short-term outcomes ${ }^{1-4}$ in patients with $\mathrm{CR}$ extend to long-term follow-up, supporting a conservative approach in these patients.

\section{Impact on daily practice}

A contained rupture after TAVI represents a rare, predominantly incidental finding on post-TAVI CTA. No adverse events related to the contained rupture were reported during long-term followup, supporting a watch-and-wait strategy in these patients.

\section{Conflict of interest statement}

F-J. Neumann reports receiving grants and non-financial support from Edwards Lifesciences. G. Pache is a consultant for Edwards Lifesiences. P. Blanke provides core laboratory services for Edwards Lifesciences. Medtronic, Neovasc, Tedyne and Aegis, for which he does not receive direct financial compensation. He is a consultant to Edwards Lifesciences, Neovasc, Tendyne, Circle Cardiovascuar Imaging. The other authors have no conflicts of interest to declare.

\section{References}

1. Blanke P, Reinöhl J, Schlensak C, Siepe M, Pache G, Euringer W, Geibel-Zehender A, Bode C, Langer M, Beyersdorf F, Zehender M. Prosthesis oversizing in balloon-expandable transcatheter aortic valve implantation is associated with contained rupture of the aortic root. Circ Cardiovasc Interv. 2012;5:540-8. 


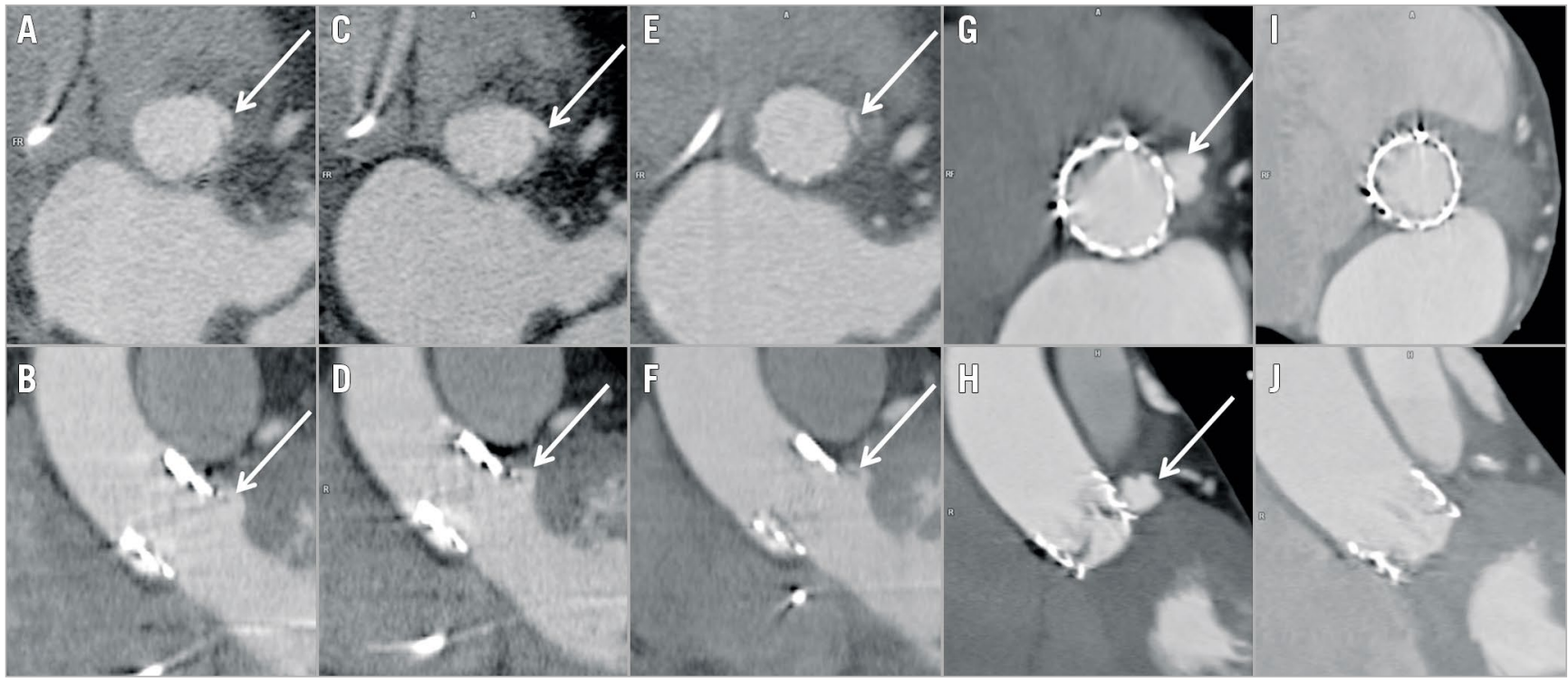

Figure 1. Typical CTA findings of contained ruptures of the aortic annulus post TAVI (arrow in A-H). The first case represents an 80-year-old female with a contained rupture diagnosed eight days post TAVI $(A \& B)$. Findings on CTA are unchanged after one $(C \& D)$ and three years $(E \& F)$. The second case demonstrates a contained rupture in a 77-year-old female diagnosed 15 days post TAVI (G \& H) with complete remission in a follow-up CTA performed eight months later $(I \& J)$.

2. Aminian A, Lalmand J, Dolatabadi D. Late contained aortic root rupture and ventricular septal defect after transcatheter aortic valve implantation. Catheter Cardiovasc Interv. 2013;81:E72-5.

3. Egenrieder S, Hill S, Backes M, Vöhringer M, Sechtem U. Contained aortic annulus rupture with persisting false aneurysm after transfemoral transcatheter aortic valve implantation. Clin Res Cardiol. 2014;103:599-601.

4. Barbanti M, Yang TH, Rodes Cabau J, Tamburino C, Wood DA, Jilaihawi H, Blanke P, Makkar RR, Latib A, Colombo A, Tarantini G, Raju R, Binder RK, Nguyen G, Freeman M, Ribeiro HB, Kapadia S, Min J, Feuchtner G, Gurtvich R, Alqoofi F, Pelletier M, Ussia GP,
Napodano M, de Brito FS Jr, Kodali S, Norgaard BL, Hansson NC, Pache G, Canovas SJ, Zhang H, Leon MB, Webb JG, Leipsic J. Anatomical and procedural features associated with aortic root rupture during balloon-expandable transcatheter aortic valve replacement. Circulation. 2013;128:244-53.

5. Himbert D, Brochet E, Serfaty JM, Vahanian A. Contained aortic root rupture after transcatheter aortic valve implantation. Eur Heart J. 2010;31:2995.

6. Bouabdallaoui N, Macron L, Durand E. An uncommon complication following transcatheter aortic valve implantation: contained aortic annulus rupture. Int J Cardiol. 2013;169:e1-2. 